\title{
A comparative study of two operative procedures in anterior hypospadias repair: limited urethral mobilization and tubularized incised plate urethroplasty.
}

\footnotetext{
1. MBBS, FCPS

Associate Professor Pediatric

Surgery

Sahiwal Medical College Sahiwal.

2. MBBS

Post Graduate Trainee Pediatric

Surgery

Children Hospital The Institute of

Child Health Lahore.

3. MBBS

House Officer

Fatima Jinnah Medical University Lahore.

4. MBBS, FCPS

Associate Professor Pediatric

Medicine

Rashid Lateef Medical College Lahore.

5. MBBS

Post Graduate Trainee Orthopedic

Surgery

Services Institute of Medical

Sciences Lahore.
}

Correspondence Address:

Dr. Shafiq ur Rehman

Associate Professor Pediatric Surgery

Sahiwal Medical College Sahiwal.

shafiqlangriyal@gmail.com

Article received on:

02/04/2021

Accepted for publication:

$21 / 07 / 2021$

\section{Shafiq ur Rehman', Fareena Ishtiaq², Zarlish Fazal ${ }^{3}$, Muhammad Anwar ${ }^{4}$, Saad Fazal ${ }^{5}$}

ABSTRACT... Objectives: This study is aimed to compare the results of limited urethral mobilization and tubularized incised plate urethroplasty in the management of anterior hypospadias, in terms of cosmetic and functional outcomes, complication rate, operative time, and hospital stay. Study Design: Prospective Randomized Controlled study. Settings: Department of Pediatric Surgery, DHQ Teaching Hospital Sahiwal. Period: January 2019 to December 2020. Material and Methods: A total of 89 patients with anterior hypospadias were included. Patients were divided randomly into two groups. In group A, limited urethral mobilization was performed and in group B, tubularized incised plate urethroplasty was carried out. A selfstructured performa was used to collect the data of all patients. Both groups were compared in terms of the operation time, hospital stay, postoperative complications, cosmetic appearance, and functional outcomes. Results: Forty-five patients were included in group A, age ranged from 2.5 to 12 years (mean 4.83years). Forty-four patients were included in group B and their ages ranged from 3.5 to 11 years (mean 4.76 years). The operation time was significantly less for group A than for group B. In group A, it ranged from 54 to 69 min with an average time of $60.51 \mathrm{~min}$ and in group $B$ from 70 to $88 \mathrm{~min}$, with an average of $79.34 \mathrm{~min}$. The mean hospital stay period in group A was 7.37 days, ranged from 7 to 9 days, and in group B was 11.04 days, ranging from 10 to 13 days. The mean follow-up period in both groups was 7.45 months, ranging from 3 months to 12 months. Meatal stenosis was the most common complication in group A, which developed in $6.66 \%(n=3)$ patients. Urethrocutaneous fistula was the most common complication in group B, which developed in $6.81 \%(n=3)$ patients. Cosmetic appearance and functional outcome were good and comparable in both groups. Conclusion: Although both techniques, tubularized incised plate and limited urethral mobilization urethroplasty are acceptable modalities for the management of anterior hypospadias. But limited urethral mobilization urethroplasty seems to be a good option due to its simplicity, short hospital stay, significant shorter operative time, low fistula formation rate, and good cosmetic and functional outcomes.

Key words: $\quad$ Anterior Hypospadias, Limited Urethral Mobilization, Snodgrass Technique.

Article Citation: Shafiq ur Rehman, Ishtiaq F, Fazal Z, Anwar M, Fazal S. A comparative study of two operative procedures in anterior hypospadias repair: limited urethral mobilization and tubularized incised plate urethroplasty. Professional Med J 2021; 28(11):1578-1584. https://doi.org/10.29309/TPMJ/2021.28.11.6506

\section{INTRODUCTION}

Hypospadias is an arrest in the normal development of the foreskin and ventral aspect of the penis. ${ }^{1}$ It is one of the most common congenital malformations of the male genitourinary system. The characteristic features are dystopic meatus, deficient hooded prepuce, and chordee. It is present in approximately one in 300 male newborns. ${ }^{2}$ Its incidence is increasing worldwide. ${ }^{3,4}$ Anterior hypospadias represents $75 \%$ of all hypospadias cases. $^{5}$
There are several surgical techniques for the repair of anterior hypospadias. More commonly practiced procedures are tubularized incised plate urethroplasty (TIP or Snodgrass technique), limited urethral mobilization urethroplasty (LUM), perimeatal based flap urethroplasty (Mathieu technique), meatal advancement and glanuloplasty incorporated (MAGPI), and glans approximation procedure (GAP).

The concept of urethral mobilization and 
advancement is very old. A technique based on this concept was first described by Beck in $1898 .{ }^{6}$ Later on, various modifications were introduced in the procedure described by Beck..$^{7,8,9}$ Limited urethral mobilization urethroplasty is a technique that has been developed on the same concept. This technique with proven benefits and effectiveness, in the terms of cosmesis and functional outcomes, is recommended for the management of anterior hypospadias by various studies. ${ }^{10,11,12,13}$ In 1994, Snodgrass first reported the tubularized incised plate urethroplasty. ${ }^{14}$ The Snodgrass technique has become the optimal surgical option to repair anterior hypospadias. ${ }^{15}$ Tubularized incised plate urethroplasty has become the most frequently used technique for the repair of anterior hypospadias. ${ }^{16,17,18}$ Tubularized incised plate urethroplasty is a versatile technique with a low complication rate and good cosmetic results. ${ }^{19,20}$ The present study is designed to compare the results of limited urethral mobilization and tubularized incised plate urethroplasty in the management of anterior hypospadias, in terms of cosmetic and functional outcomes, complication rate, operative time, and hospital stay.

\section{MATERIAL \& METHODS}

This is a prospective randomized controlled study conducted at the Department of Pediatric Surgery, DHQ Teaching Hospital Sahiwal from January 2019 to December 2020. A total of 89 patients with anterior hypospadias were included. Patients were divided randomly into two groups. In group $A$, limited urethral mobilization was performed and in group $B$, tubularized incised plate urethroplasty was done.

\section{Inclusion Criteria}

1. The patients with anterior hypospadias (glanular, coronal, sub coronal, distal penile shaft variety).

2. The patients with mild chordee and torsion.

\section{Exclusion Criteria}

1. The patients with midshaft and proximal hypospadias.

2. The patients of anterior hypospadias with severe chordee (more than 30 degrees).
3. The patients with severe comorbidities.

4. The patients with a previous history of hypospadias surgery and already circumcised.

A self-structured performa was used to collect the data of all patients. Preoperative evaluation of every patient was done by history, physical examination, and investigations. Informed consent was taken for all patients from their parents/guardians. The study was approved by the ethical review committee, Sahiwal medical college Sahiwal. (2686/SMC/SWL)

\section{Surgical Technique}

All procedures performed under general anesthesia and standard antiseptic measures adopted. A preoperative antibiotic was given to all patients before induction of anesthesia. The penile tourniquet was used in both techniques and was removed when glans reconstruction was completed.

\section{Limited Urethral Mobilization Urethroplasty}

A traction suture was applied at the tip of the glans with 4/0 vicryl. A feeding tube of approximately 6-8 Fr was passed in the meatal opening. The urethral meatus was circumscribed and the urethra was mobilized through the avascular plane between the corpora cavernosa and corpus spongiosum. Sufficient length was achieved to allow the urethra to reach the tip of the glans. Penile skin was degloved. Glanular wings were mobilized and prepared to receive the mobilized urethra. The dorsal lip of the urethra was sutured to the glanular tip with 5/0 vicryl in an interrupted fashion. In patients with chordee, penile skin was degloved down to the penoscrotal junction to relieve the chordee. Dorsal plication was performed in selected cases. The stent was secured with a glanular suture which was previously placed on glans for traction.

\section{Tubularized Incised Plate Urethroplasty}

After applying traction suture at the tip of glans, $U$ shaped incision was made along with the urethral plate. Then incision was extended beyond the mid glans. The urethral plate was widened by a midline incision along its length. A circumferential 
incision was made proximal to the coronal sulcus. Penile skin was degloved. Glanular wings were developed. The dorsal dartos flap was dissected from the prepucial skin. A feeding tube of size $6-8 \mathrm{Fr}$ was used as a catheter. The urethral plate was tubularized over the feeding tube. Neourethra was covered with dartos flap. The two glanular wings were approximated in the midline over the neourethra. Penile skin was reapproximated. After the completion of the procedure, the urethral stent was fixed with traction suture already applied to the tip of the glans.

Standard postoperative care was given to patients of both groups. Intravenous antibiotic (ceftriaxone, amoxicillin: clavulanic acid) was given throughout the hospitalized period. Intravenous paracetamol and oral ibuprofen was used for analgesia. Oxybutynin was used selectively. The catheter was removed on the 7-9th day in group $A$ and 10-13th day in group B patients. The minimum follow up for all the patients was three months. A vertically oriented slit-like meatus and conicalshaped glans were considered a good cosmetic appearance. Functional outcome was evaluated with a forward-directed good stream of urine from the tip of the glans. Complications were noted over the period of time.

\section{Statistical Analysis}

Data were analyzed using a statistical program for social science version 24. Quantitative data were shown as mean standard deviation (SD). Qualitative data were shown as frequency and percentage.

\section{RESULTS}

A total of 89 patients with anterior hypospadias were included in this study, $09(10.11 \%)$ were glandular, 32 (35.95\%) were coronal, 31 (34.83\%) were sub coronal and 17 (19.10\%) were distal penile shaft variety hypospadias (Table-I). Forty-five patients were included in group $A$, who underwent limited urethral mobilization urethroplasty and their age ranged from 2.5 to 12 years (mean 4.83 years). Forty-four patients were included in group $B$ and tubalarized incised plate urethroplasty was carried out and their ages ranged from 3.5 to 11 years (mean 4.76 years). The operation time was calculated after the completion of the induction of anesthesia. It was significantly less for group $A$ than for group B. In group A, it ranged from 54 to 69 min with an average time of $60.51 \mathrm{~min}$ and in group $B$ from 70 to 88 min with an average of $79.34 \mathrm{~min}$. The mean hospital stay period in group A was 7.37 days, ranged from 7 to 9 days, and in the group, $B$ was 11.04 days, ranged from 10 to 13 days. The mean follow-up period in both groups was 7.45 months, ranging from 3 months to 12 months (Table-II). Meatal stenosis was the most common complication in group $A$, which developed in $6.66 \%(n=3)$ patients. Detail of complications in group $A$ is given in Table-III. Urethrocutaneous fistula was the most common complication in group $B$, which developed in $6.81 \%(n=3)$ patients. Detail is shown in Table-VI. A vertically oriented slit-like meatus and conical glans were considered as good cosmetic appearance and a direct urinary stream was accepted as a good functional outcome. Detailed results of group A and group B are shown in Table-V and VI respectively.

\begin{tabular}{|l|c|c|c|}
\hline \multicolumn{1}{|c|}{ Type } & \multicolumn{1}{|c|}{ Total } & $\begin{array}{c}\text { Group A } \\
(\mathbf{n = 4 5 )}\end{array}$ & $\begin{array}{c}\text { Group B } \\
(\mathbf{n = 4 4 )}\end{array}$ \\
\hline Glanular & $09(10.11 \%)$ & $5(11.11 \%)$ & $4(9.09 \%)$ \\
\hline Coronal & $32(35.95 \%)$ & $15(33.33 \%)$ & $17(38.63 \%)$ \\
\hline Sub Coronal & $31(34.83 \%)$ & $16(35.55 \%)$ & $15(34.09 \%)$ \\
\hline $\begin{array}{l}\text { Distal Penile } \\
\text { Hypospadias }\end{array}$ & $17(19.10 \%)$ & $09(20.00 \%)$ & $08(18.18 \%)$ \\
\hline
\end{tabular}

Table-I. Types of Hypospadias.

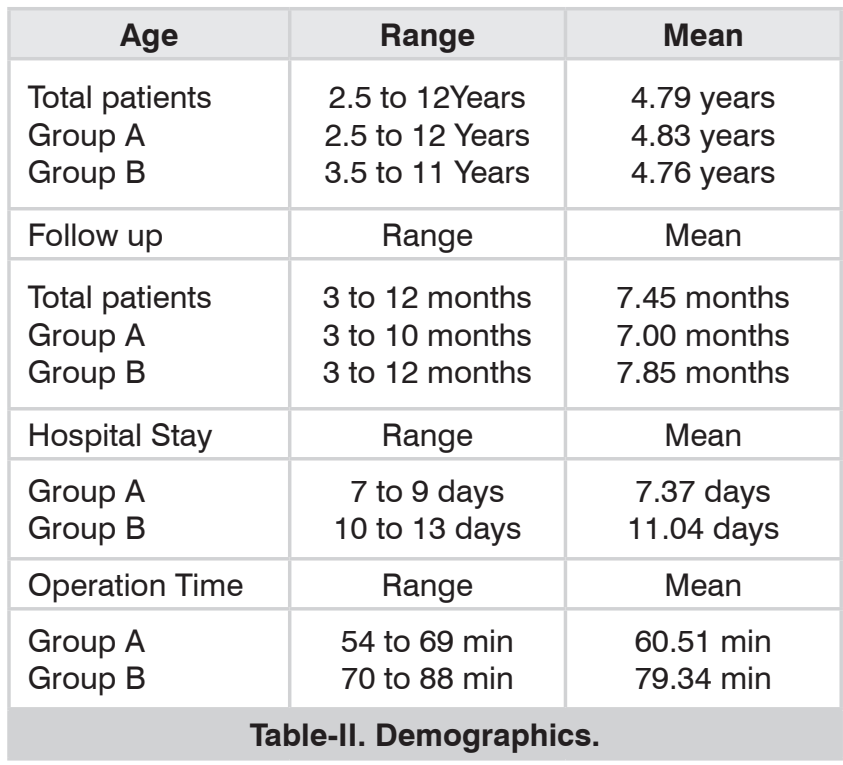




\begin{tabular}{|l|c|}
\hline \multicolumn{1}{|c|}{ Post OP Complications } & Number (\%) \\
\hline Wound Infection & $2(4.44 \%)$ \\
\hline Complete Glanular Disruption & $1(2.22 \%)$ \\
\hline Partial Glanular Disruption & $1(2.22 \%)$ \\
\hline Meatal Stenosis & $3(6.66 \%)$ \\
\hline Urethro cutaneous fistula & $1(2.22 \%)$ \\
\hline
\end{tabular}

Table-III. Group A: $\eta=45$ Post-Operative Complications.

\begin{tabular}{|l|c|}
\hline \multicolumn{1}{|c|}{ Post OP Complications } & Number (\%) \\
\hline Urethrocutaneous fistula & $3(6.81 \%)$ \\
\hline Wound Infection & $3(6.81 \%)$ \\
\hline Meatal Stenosis & $2(4.54 \%)$ \\
\hline Devitalized skin flap & $1(2.27 \%)$ \\
\hline Complete glanular disruption & $1(2.27 \%)$ \\
\hline Partial glanular disruption & $1(2.27 \%)$ \\
\hline Haematoma & $1(2.27 \%)$ \\
\hline Persistent chordee & $1(2.27 \%)$ \\
\hline
\end{tabular}

Table-IV. Group B $\eta=44$ Post-Operative Complications.

\begin{tabular}{|c|c|}
\hline Cosmetic Appearance & Number (\%) \\
\hline Slit like, vertically oriented meatus & 42 (93.33\%) \\
\hline Conical glans & $43(95.45 \%)$ \\
\hline Functional outcome & Number (\%) \\
\hline Straight, forward directed voiding & 42 (93.33\%) \\
\hline \multicolumn{2}{|c|}{$\begin{array}{l}\text { Table-V. Group A: } \eta=45: \text { Cosmetic appearance ano } \\
\text { functional outcome. }\end{array}$} \\
\hline Cosmetic Appearance & Number (\%) \\
\hline Slit like, vertically oriented meatus & 42 (95.45\%) \\
\hline Conical glans & 42 (95.45\%) \\
\hline Functional outcome & Number (\%) \\
\hline Straight, forward directed voiding & 39 (88.63\%) \\
\hline \multicolumn{2}{|c|}{$\begin{array}{l}\text { Table-VI. Group B } \eta=44 \text { Cosmetic appearance and } \\
\text { functional outcome. }\end{array}$} \\
\hline
\end{tabular}

\section{DISCUSSION}

Tubularized incised plate urethroplasty is a widely preferred and practiced technique for anterior hypospadias. It has a wide range of indications in distal, mid-penile, and even proximal hypospadias. However, this technique is more traumatic and has the disadvantage of a ventral suture line. It is also not suitable for patients with shallow urethral plates and smallsized glans. Whereas limited urethral mobilization has limited indications and only useful in anterior hypospadias. The advantages of this technique are, use of native elastic urethra and the ability to remove dysplastic ventral elements, if present. Technically it is simple and less traumatic. In this study, we compared the outcomes of these two commonly practiced techniques for anterior hypospadias.

In the present study, out of total 89 patients of anterior hypospadias, $10.11 \% \quad(n=09)$ were glandular, 35.95\% $(n=32)$ coronal, 34.83\% $(n=31)$ sub coronal and $19.10 \%(n=17)$ distal penile hypospadias. Almost similar results reported by Ismail et at 2020 , glandular $13.1 \%(n=10)$, coronal $50 \%(n=38)$, sub coronal $27.6 \%(n=21)$ and $9.2 \%$ $(n=7)$ were recurrent distal hypospadias. ${ }^{21}$ In our study recurrent hypospadias were not included. Coronal hypospadias is the most common variety in both studies. In variance with this result, sub coronal hypospadias was reported as the most common variety, $56.25 \%(n=9)$, in another study. ${ }^{22}$

In our study, out of a total of 89 patients, age ranged from 2.5 to 12 years (mean age 4.79 years). In group A, age ranged from 2.5 to 12 years with a mean age of 4.83 years. Whereas in group $B$, age ranged from 3.5 to 11 years with a mean age of 4.76 years. Al- Shahat et al conducted a comparative study in which eight patients were allocated for the Snodgrass technique and their age ranged between 12 months to 9 years (mean 3.6 years). In the second group, the urethral advancement procedure was carried out, and reported age ranged between 12 months to 12 years (mean 3.2 years). ${ }^{23}$ The reported hospital stay in the present study was 7 to 9 days (mean 7.37 days) for group $A$ and 10 to 13 (mean 11.04 days) days for group B. Shorter hospital for limited urethral mobilization urethroplasty and longer for Snodgrass technique has been reported in many published studies. ${ }^{10,23,24}$ The mean operative time was significantly less in group $A$. It ranged from 54 to $69 \mathrm{~min}$ (mean $60.51 \mathrm{~min}$ ) in group $A$ and 70 to 88 min (mean 79.34 min) in group B. In a comparative study conducted by Al-Shahat et al, operative time was reported as $56.9+7.5 \mathrm{~min}$ for urethral advancement procedure and $76.9+10$. 3 min for tubalarized incised plate urethroplasty. ${ }^{23}$ Short operation duration for limited urethral mobilization urethroplasty has been reported in the published literature. ${ }^{21,22,25}$ 
Regarding the postoperative complications, urethrocutaneous fistula was noted in 01 patients $(2.22 \%)$ in group A and 03 patients $(6.81 \%)$ in group B. Karim S, reported urethrocutaneous fistula in $1.47 \%$ of patients with limited urethral mobilization urethroplasty and $14.29 \%$ patients with modified Snodgrass repair. ${ }^{26}$ High incidence of urethrocutaneous fistula with tubularized incised plate urethroplasty and low with limited urethral mobilization urethroplasty, as reported in our study, is in accordance with results obtained by many series. ${ }^{10,21,22,24,25,27,28}$ Meatal stenosis is another important complication that has been reported with both techniques. ${ }^{10,20,21,23,25,29}$ Meatal stenosis was noted in 03 patients $(6.66 \%)$ in group A and 02 patients (4.54\%) in group B. Wound infection was noted in 02 patients $(4.44 \%)$ in group $A$ and 03 patients $(6.81 \%)$ in group $B$. Haque et al reported wound infection in 20 patients(5\%) with modified Snodgrass repair [20]. Haider et al reported wound infection in 01 patients $(1.6 \%)$ with the urethral mobilization technique. ${ }^{11}$ Due to the preservation of the urethral plate, restricted chordee correction is the main limitation of tubularized incised plate urethroplasty. In this technique, dorsal plication is the only option available to correct the chordee. Whereas in limited urethral mobilization urethroplasty, urethral mobilization is also helpful in correcting chordee. That is why the reported incidence of persistent chordee with this technique is low. In our study, persistent chordee was not seen in any patient in group A. Similar to our result, persistent chordee was also not noted in any patient in studies conducted by Ur Rehman et al and Chakraborty et al. ${ }^{10,12}$ Persistent chordee was seen in 01patient $(2.27 \%)$ in group B. AbouZeid AA reported persistent chordee in 06 patients $(3.1 \%)$ following tubularize incised plate urethroplasty. ${ }^{27}$ Good and comparable cosmetic and functional outcomes were achieved in both groups, table no V and VI. Results are in accordance with published literature. 10,12,25,29

The small sample size is a limitation of our study. Fifty-six patients were included in the first year of the study period, whereas due to the covid-19 pandemic, only thirty-three patients with distal hypospadias were operated on in the second year of the study. However, more studies with a good sample size are required to validate the results of this study.

\section{CONCLUSION}

Although both techniques, tubularized incised plate, and limited urethral mobilization urethroplasty are acceptable modalities for the management of anterior hypospadias. However, tubularized incised plate urethroplasty is a more traumatic technique. It also needs the use of dartos fascia as a barrier layer. Inappropriate dissection of dartos fascia may lead to devascularization of the penile skin. Whereas limited urethral mobilization urethroplasty seems to be a good option due to its simplicity, short hospital stay, significant shorter operative time, low fistula formation rate, and good cosmetic and functional outcomes.

Copyright $\odot 21$ July, 2021.

\section{REFERENCES}

1. Baskin LS, Ebbers MB. Hypospadias: Anatomy, etiology, and technique. J Pediatr Surg 2006; 41:46372. DOI: 10.1016/j.jpedsurg.2005.11.059.

2. Iqbal T, Nasir U and Khan M. Frequency of complications in Snodgrass repair and its risk factors. Pakistan Journal of Surgery 2011; 27(3):188-93.

3. Seiboid J, Boehmer A, Veger A, Merseburger AS, Stenzl $A$, Sievert KD. The meatal mobilization technique for coronal/subcoronal hypospadias repair. BJU Int 2007; 100:164-167. DOI: 10.1111/j.1464-410X.2007.06790.x.

4. Kraft KH, Shukla AR, Canning DA. Hypospadias. Urol Clin North Am 2010; 37(2):167-181. DOI: 10.1016/j. ucl.2010.03.003.

5. Alkan M, Qguzkurt P, Ezer SS, Ince Hicsonmez A. Evaluation of the results of eccentric circummeatalbased flap with combined limited urethral mobilization technique for distal hypospadias repair. J Pediatr Urol 2008; 3:206-209. DOl:https://doi. org/10.1016/j.jpurol.2007.11.008.

6. Beck C. A new operation for balanic hypospadias. New York Med J 1898; Jan:147-8.

7. Koff SA. Mobilization of urethra in the surgical treatment of hypospadias. J Uro. 1981; 125:394-7.

8. Nsrallah PF, Minott HB. Distal hypospadias repair. J Urol.1984; 131:928-30. 
9. Atala A. Urethral mobilization and advancement for midshaft to distal hypospadias. J Urol. 2002; 168:1738-41; discussion 1741. DOI: 10.1097/01. ju.0000023971.96439.b8.

10. Ur-Rehman S, Makki Y, Ishtiaq F, Shamikha W, Aziz N, Fazal S. The outcome of limited Urethral Mobilization urethroplasty for anterior hypospadias. The Professional Med J 2020; 27(1):210-216. DOI: 10.29309/ TPMJ/2020.27.1.4055.

11. Haider N, Hashim I, Iqbal MA, Wasti AR, Chaudhary SH, Ahmad A, et al. Outcome of urethral mobilization and advancement after anterior hypospadias surgery. Annals of Pediatric Surgery. 2019; 15(1):6.

12. Chakraborty AK, Majumdar SK, Zahid MK, Biswas I, Palit P. Limited urethral mobilization technique in distal hypospadias repair: An overview. Chattagram MaaO-Shishu Hospital Medical College Journal. 2017; 16(1):37-41. DOI: https://doi.org/10.3329/cmoshmcj. v16i1.34985

13. Karim S, Aziz MA, Parvin S, Hasan S, Islam N. Limited Urethral Mobilization (LUM) Technique for repair of distal penile hypospadias: Experiences of tertiary care paediatric Hospital. DS(Child) H J 2017;33(1):4853.

14. Snodgrass W. Tubularized incised plate urethroplasty for distal hypospadias. J Urol 1994; 151:464-465. DOI: 10.1016/s0022-5347(17)34991-1.

15. Shuzhu C, Min W, Yidong L et al. Selecting the right method for hypospadias repair to achieve optimal results for the primary situation. SpringerPlus. 2016 Dec; 5(1):1624.

16. Gong EM, Cheng EY. Current challenges with proximal hypospadias: We have a long way to go. J Pediatr Urol 2017; 13:457-467.

17. Steven L, Cherian A, Yankovic F, Mathur A, Kulkarni M, Cuckow $P$. Current practice in paediatric hypospadias surgery: A specialist survey. J Pediatr Urol 2013; 9: 1126-1130.

18. Springer A, Krois W, Horcher E. Trends in hypospadias surgery: Results of a worldwide survey. Eur Urol 2011; 60: 1184-1189.

19. AbouZeid AA. Tubularized incised plate urethroplasty for primary hypospadias repair: Versatility versus Limitations. The Journal of Genital Surgery. 2019; 1(Ready articles):1-9.
20. Haque AU, Akbar F, Raheem S, Hussain M, Nadeem M, Alam K, Haq IU. Modified snodgrass repair for hypospadias: Outcome at a general surgical unit. Journal of Saidu Medical College. 2020 Dec 13; 10(2).

21. Ismail O, Mohammed NH, Salim MJ. The Meatal Mobilization (MEMO) technique for distal primary and recurrent hypospadias. PJMHS 2020; 14(3):131821.

22. Thakur D. Outcome of snodgrass repair in distal hypospadias-an institutional experience. Journal of Society of Surgeons of Nepal. 2018; 21(2):28-31.

23. Alngaar $Y$, Alshahat $O$, Zayid T. A comparative study between Snodgrass and urethral advancement methods in the repair of distal penile Hypospadias. Al-Azhar International Medical Journal. 2020; 1(1):143148.

24. Hashish MS, Elsawaf MI, Moussa MA. Urethral advancement procedure in the treatment of primary distal hypospadias: A series of $\mathbf{2 0}$ cases. Annals of Pediatric Surgery. 2017; 13(1):29-37.

25. Awad MMS, Tolba AM, Saad KM, Zaghlol MR, Rozigque $\mathrm{AE}, \mathrm{Gharib} \mathrm{OH}$, et al. What is the best choice for repair of distal penile hypospadias: The tubularized incised plate urethroplasty or anterior urethral advancement technique? Indian J Plast Surg. 2007; 40(2):182-188.

26. Karim S, Aziz A, Rehman A, Parvin S. Limited urethral mobalization (lum) and modified tabularized incised plate (tip) urethroplasty in distal hypospadias repair; A comparative study. IJCMPR 2017; 3(8):2232-34.

27. AbouZeid AA. Tubularized incised plate urethroplasty for primary hypospadias repair: Versatility versus Limitations. The Journal of Genital Surgery. 2019; 1(Ready articles):1-9.

28. Sheikh MA, Latif MA, Ahmad JAM. Hypospadias repair in children: 10-years' experience at Shaikh Zayad Hospital Lahore. Professional Med J 2019; 26(7):1020-1026. DOI: https://doi.org/10.29309/ TPMJ/2019.26.07.1622.

29. Yadigar MA, Abbas YI, Aljomaily FSS. Tubularized incised plate (Snodgrass) urethroplasty as the surgical technique of choice for repair of distal and midshaft hypospadias in Tikrit Teaching Hospital. Diyala Journal of Medicine. 2019; 16(1):63-9. 


\section{AUTHORSHIP AND CONTRIBUTION DECLARATION}

\begin{tabular}{|c|c|c|c|}
\hline No. & Author(s) Full Name & Contribution to the paper & Author(s) Signature \\
\hline 2 & Fareena Ishtiaq & $\begin{array}{l}\text { Conception and design, acquisition } \\
\text { of data, Drafting literature review } \\
\text { and final. } \\
\text { Approval of article, Literature } \\
\text { review, Data analysis, Proof } \\
\text { reading. }\end{array}$ & $h$. \\
\hline 3 & Zarlish Fazal & $\begin{array}{l}\text { Literature search and reivew, Proof } \\
\text { reading. }\end{array}$ & Anvar \\
\hline 4 & Muhammad Anwar & $\begin{array}{l}\text { Conception of idea, final approval } \\
\text { of the version to the published. }\end{array}$ & \\
\hline 5 & Saad Fazal & $\begin{array}{l}\text { Literature search and review, } \\
\text { Revising manuscript critically. }\end{array}$ & $x$ \\
\hline
\end{tabular}

